\title{
Pain Scores of Scalpel versus Diathermy Skin Incisions in Head and Neck Surgeries
}

\author{
Furqan Mirza ${ }^{1}$, Syeda Beenish Bareeqa ${ }^{1 *}$, Muhammad Junaid Alam² ${ }^{2}$ Syed Iqbal Hussain ${ }^{3}$ and Syed Ijlal Ahmed ${ }^{4}$ \\ ${ }^{1}$ Jinnah Medical and Dental College, Pakistan \\ ${ }^{2}$ PAF Hospital Rafiqui, Pakistan \\ ${ }^{3}$ Dow University of Health and Sciences, Pakistan \\ ${ }^{4}$ Liaquat National Medical College and Hospital, Pakistan \\ Submission: June 11, 2018; Published: June 21, 2018 \\ *Corresponding author: Syeda beenish Bareeqa, Jinnah Medical and Dental College, 21-22 Shaheed-e-millat Road, Karachi, Pakistan, \\ Email: syedabeenishbareeqa@gmail.com
}

\begin{abstract}
Introduction and Objective: Head and neck surgeries, as other surgeries, require an incision of sufficient length to allow the surgeon a good view of the operating field and to permit the visibility of important structures like nerves and large arteries. The objective of this study is to compare mean pain score with scalpel verses diathermy method of head and neck surgeries on 1st postoperative day.

Subjects And Methods: All patients with the age 18 years to 60 years, of either gender underwent Head and Neck surgeries (Thyroidectomy, neck dissection, excision of neck mass), duration of surgery less than or equal to 1 hour and Incision size 5-10cms were included. The patients were assigned into either group A (diathermy incision) or group B (scalpel incision). Pain score was noted on 1st post-operative day by numerical analogue scale for pain.

Results: Mean age of the patients in diathermy group was 39.26+/-7.04 years while in scalpel was 45.96+/-5.28 years. There were 33 (55\%) male patients while 27 (45\%) female patients. Mean pain score in diathermy group was 4.10+/-0.71 while in scalpel group 6.86+/-0.62. Unpaired t-test was applied and statistically sufficient of evidence of significant relationship was observed as p-value was found to be less than level of significance (p-value $<0.001)$.
\end{abstract}

Conclusion: There is strong difference in the mean pain score in scalpel verses diathermy in head and neck surgeries on 1st postoperative day.

Keywords: Head and Neck Surgeries; Scalpel; Diathermy; Mean pain score; Numerical analogue scale (NAS)

\section{Introduction}

Head and neck surgeries as other surgeries require an incision of sufficient length to allow the surgeon a good view of the operating field and to permit the visibility of important structures like nerves and large arteries.

Conventionally the most common method of making the incision is using the scalpel. In recent time, diathermy, LASER and harmonic scalpels are being widely used as an alternative method for incisions in head and neck [1-3]. The use of electricity in medicine coincided with the earliest scientific discoveries, beginning in the 18th century [4]. Then, Goldwyn described three eras encompassing the development of the modern electrosurgical technology [5]. The first era began with the discovery and use of static electricity. The second era, best called "galvanization," evolved from Luigi Galvani's accidental discovery in 1786 . The third era, dating to 1831 , was ushered in with discoveries by Faraday and Henry in England and America, respectively, who almost simultaneously showed that a moving magnet could induce an electrical current in wire.

Electro surgery has been described as high-frequency electrical current passed through tissue to create a desired clinical effect. As the current is delivered, it passes through the tissues to produce heat. This differs from electrocautery, in which electrical current heats an instrument and a clinical effect is realized when the heated tool is applied to the tissues [6]. Diathermy use is characterized by high frequency current that passes through the tissues by applying an active electrode which excites the tissue molecules creating heat energy [7]. Harmonic scalpel based upon the principle of high frequency ultrasonic waves utilization [7]. Head and neck surgeries are associated with a number of complications like wound dehiscence, wound infection and compromised cosmesis [9]. but post-operative 
pain is being the most popular feature associated with any surgery which can create significant discomfort for patient in the immediate postoperative period and also increases patient morbidity [10]. A good pain control will not only help to decrease patient's distress but lead to reduced stress response important in patients to preserve their quality of life [10].

Diathermy usage has nowadays been gaining favor as it is efficient, is easily available, causes reduced bleeding and leads to minimized superficial infections [11]. In one study the mean pain score after using diathermy skin incision on third postoperative day was $4.34 \pm 0.81$ in diathermy group versus $7.10 \pm 0.66$ in scalpel group $(\mathrm{p}<0.05)[8]$. Pearlman and associates published data that support the use of electro surgery as compared with scalpel or CO2 laser in opening tissues after skin incision with the scalpel [12]. Kearns and colleagues showed that patients opened with mono polar electrosurgical pencil electrodes (Bovies) for laprotomy had comparable rates of wound infection to those opened with scalpel and lower pain scores immediately postoperatively on days 1 and 2. [13]. In another international study, postoperative pain and complication rate were comparable for both the groups [14]. The data on this topic is controversial as discussed above, some studies favors the incision by harmonic scalpel whereas other studies showed no difference in harmonic and conventional technique regarding postoperative pain $[7,8,11,14]$.

Furthermore, there is a gap in knowledge regarding scalpel versus diathermy in developing countries where the affordability does play a significant role in determining the surgical technique used. Therefore the rationale of this study is to determine the mean post-operative pain scores in patients with scalpel verses diathermy skin incisions to provide supportive local evidence for the use of this simple technique, which will help to reduce the post operative pain and thus results in decreased use of analgesics, reduced stress response and early rehabilitation of the patient and decreases the overall morbidity in early post operative period. The objective of this study is to compare mean pain score in scalpel verses diathermy skin incisions in head and neck surgeries on $1^{\text {st }}$ postoperative day.

\section{Material And Methods}

A randomized double blind controlled trial was conducted on 60 patients who presented to the Department of head and neck surgery, Civil Hospital, Karachi. After the approval of Institutional review board (IRB) of Dow University of Health and Sciences, the study was conducted in the period of six months starting from January 2015 to June 2015. Patients were enrolled in study when informed consent was taken. The purpose, procedure, risk and benefits of the study and surgery were explained meanwhile the assurance of confidentiality was disclosed to the patients. All patients with the age of 18 years to 60 years, undergoing Head and Neck surgeries (Thyroidectomy, neck dissection, excision of neck mass), with the duration of surgery $\leq 2$ hours and with the incision size of $5-10 \mathrm{~cm}$ were included in this study whereas patients having co-morbidities (e.g. Ischemic heart disease, Diabetes Mellitus, Hypertension), history of previous head and neck surgery, ongoing chemo or radiotherapy and blood dyscrasias were excluded from our research.

The patient was assigned into either group A (diathermy incision) or group B (scalpel incision) by using sealed opaque envelops having slips of group A and B within. Patients were asked to pick one envelop on entering the operation theater and was assigned to the respective group. After optimization and induction of anesthesia, patients of both groups underwent surgery which was performed by the postgraduate trainee of 3-4 years under supervision of senior consultant. Patients of both groups received $2 \%$ xylocaine with adrenaline infiltrated into the site of incision, and were given similar pain management in the form of diclofenac $75 \mathrm{mg}$ intramuscular injection 8 hourly post-operatively. Patients were discharged on $2^{\text {nd }}$ postoperative day. Providing with instructions about the usage of numerical analogue scale, patients were asked to mark their responses on $1^{\text {st }}$ post-op day before the administration of analgesics. Demographic data including age and gender was also recorded on designed questionnaire. Statistical analysis was performed by using SPSS for Windows (version 16). Unpaired student t-test was applied to compare the mean difference of postoperative pain scores between two groups.

\section{Results}

Mean age of the patients in diathermy group was 39.26 \pm 7.04 years while in scalpel group was $45.96 \pm 5.28$ years. There were 33 (55\%) male patients while 27 (45\%) female patients. Graphical presentation is given in (Figure 1). Years of residency of surgeon for most of the patients was IV, i.e. 39 (65\%) while $21(35 \%)$ was III. Mean duration of disease in diathermy group was $1.30 \pm 0.65$ years while in scalpel group, it was $1.10 \pm 0.66$ years. Mean duration of surgery in diathermy group was 125.70 \pm 9.53 minutes while in scalpel group was $134.56 \pm 9.64$ minutes. Mean pain score in diathermy group was $4.10 \pm 0.71$ while in scalpel group $6.86 \pm 0.62$. Unpaired t-test was applied and statistically significant evidence of difference was observed as the p-value was $<0.001$. Statistical details are given in (Table 1 ). Stratification was done with regard to age, gender, duration of disease, duration of surgery and year of residency of surgeon to control effect modifiers. Student's t-test was again applied and statistically significant evidence was observed as p-values were mostly found to be significant ( $\mathrm{p}$-value $<0.001$ ). The details of analysis are given in (Table 2-6).

Table 1: Comparison of Pain Scores in Both Groups.

\begin{tabular}{|c|c|c|c|c|c|}
\hline Groups & $\begin{array}{c}\text { Pain } \\
\text { scores }\end{array}$ & $\begin{array}{c}\text { Mean } \\
\text { difference }\end{array}$ & p-value & $\begin{array}{c}\mathbf{9 5 \%} \\
\text { (C.I) }\end{array}$ \\
\hline (n=60) & Mean & S.D & & & \\
\hline Diathermy & 4.1 & 0.71 & -2.7 & 0.001 & $\begin{array}{c}-3.11 \text { to } \\
-2.41\end{array}$ \\
\hline Scalpel & 6.86 & 0.62 & & & \\
\hline
\end{tabular}




\section{Global Journal of Otolaryngology}

Table 2: Comparison of Pain Score as Per Age of the Patient.

\begin{tabular}{|c|c|c|c|c|c|c|}
\hline & Groups & $\mathbf{n}$ & Pain score & & p-value & 95\% (C.I) \\
\hline AGE & & & Mean & S.D & & -2.87 to -4.52 \\
\hline$\leq 40$ YEARS & Scalpel & 9 & 7.8 & 0.44 & 0.001 & \\
\hline (n=29) & Diathermy & 20 & 4.1 & 0.85 & & -2.24 to -2.91 \\
\hline$>40$ YEARS & Scalpel & 18 & 6.68 & 0.47 & 0.001 & \\
\hline
\end{tabular}

Table 3: Comparison of pain score as per duration of head and neck disease.

\begin{tabular}{|c|c|c|c|c|c|c|c|c|}
\hline Duration & Group & $\mathbf{n}$ & Pain score & & & & p-value & 95\% (C.I) \\
\hline & & & Mean & S.D & & & & \\
\hline DISEASE of $\leq 1$ YEARS & Scalpel & 22 & 3.86 & & & 2.21 & 0.584 & -1.16 to 0.65 \\
\hline$(\mathrm{n}=49)$ & Diathermy & 27 & 4.11 & & & 0.75 & & \\
\hline DISEASE of $>1$ YEARS & Scalpel & 8 & 7.5 & & 0.53 & & 0.001 & -2.77 to -4.22 \\
\hline$(\mathrm{n}=60)$ & Diathermy & 3 & 4 & & 0 & & & \\
\hline
\end{tabular}

Table 4: Comparison of Pain Score as Per Duration of Surgery (In Min).

\begin{tabular}{|c|c|c|c|c|c|c|c|c|}
\hline Duration & Group & $\mathbf{n}$ & Pain score & & & & p-value & 95\% (C.I) \\
\hline & & & Mean & S.D & & & & \\
\hline DISEASE of $\leq 1$ YEARS & Scalpel & 22 & 3.86 & & & 2.21 & 0.584 & -1.16 to 0.65 \\
\hline$(n=49)$ & Diathermy & 27 & 4.11 & & & 0.75 & & \\
\hline DISEASE of $>1$ YEARS & Scalpel & 8 & 7.5 & & 0.53 & & 0.001 & -2.77 to -4.22 \\
\hline$(\mathrm{n}=60)$ & Diathermy & 3 & 4 & & 0 & & & \\
\hline
\end{tabular}

Table 5: Comparison of Pain Score As Per Years Of Residency of Performing Surgeon.

\begin{tabular}{|c|c|c|c|c|c|c|c|c|}
\hline Duration & Group & $\mathbf{n}$ & Pain score & & & & p-value & 95\% (C.I) \\
\hline DISEASE of $\leq 1$ YEARS & & & Mean & S.D & & & & \\
\hline$(\mathrm{n}=49)$ & Scalpel & 22 & 3.86 & & & 2.21 & 0.584 & -1.16 to 0.65 \\
\hline DISEASE of $>1$ YEARS & Diathermy & 27 & 4.11 & & & 0.75 & & \\
\hline$(\mathrm{n}=60)$ & Scalpel & 8 & 7.5 & & 0.53 & & 0.001 & -2.77 to -4.22 \\
\hline
\end{tabular}

Table 6: Comparison of Pain Score As Per Gender.

\begin{tabular}{|c|c|c|c|c|c|c|c|c|}
\hline Duration & Group & $\mathbf{n}$ & Pain score & & & & p-value & 95\% (C.I) \\
\hline & & & Mean & S.D & & & & \\
\hline DISEASE of $\leq 1$ YEARS & Scalpel & 22 & 3.86 & & & 2.21 & 0.584 & -1.16 to 0.65 \\
\hline$(n=49)$ & Diathermy & 27 & 4.11 & & & 0.75 & & \\
\hline DISEASE of > 1 YEARS & Scalpel & 8 & 7.5 & & 0.53 & & 0.001 & -2.77 to -4.22 \\
\hline$(n=60)$ & Diathermy & 3 & 4 & & 0 & & & \\
\hline
\end{tabular}

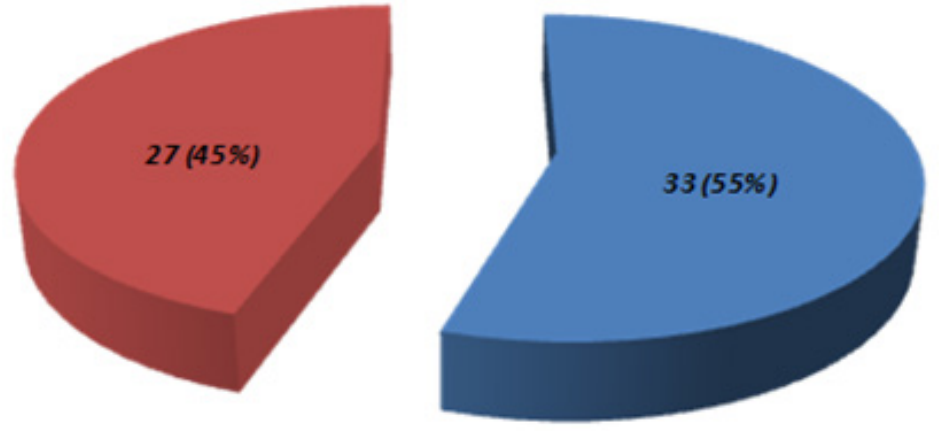

Figure 1: Gender Distribution. 


\section{Global Journal of Otolaryngology}

\section{Discussion}

Diathermy usage has nowadays been gaining favor as it is efficient, easily available, minimal post-op bleeding and have reduced incidence of superficial infections [11]. In a study by Salami A et al, mean pain score after using diathermy skin incision on third postoperative day was $4.34 \pm 0.81$ in diathermy group versus $7.10 \pm 0.66$ in scalpel group $(p<0.05)$ [8]. In a similar study conducted by prompt $\mathrm{D}$ and associates, postoperative pain and complication rate were comparable for both the groups [14]. In our study, mean pain score in diathermy group was $4.10 \pm 0.71$ while in scalpel group $6.86 \pm 0.62$. Student's $\mathrm{t}$-test was applied which showed statistically significant (p-value $<0.001$ ) difference among two groups. Several studies also have supported our results. According to Kearns and colleagues an electrosurgical incision can be used with good results during laparotomy as compared with scalpel incisions. In this study, patients opened with mono polar electrosurgical pencil electrodes (Bovies) had comparable rates of wound infection to those opened with scalpel and lower pain scores immediately postoperatively on days 1 and 2 [13].

Similarly, Pearlman and associates published data that support the use of electro surgery as compared with scalpel or $\mathrm{CO}_{2}$ laser in opening tissues after skin incision with the scalpel. Open cheeky stectomy wounds carried deeper with electro surgery had significantly faster incision times and significantly less incisional blood loss as compared with those done with scalpel or laser, with no significant difference in subjective or objective patient pain. The benefits of such data supporting the exclusive use of electro surgery at laparotomy in this era of increased rates of surgical exposure to hepatitis C-, hepatitis B-, and HIV-infected patients should be evident. The recent application of bipolar electro surgery in the sealing of vessels has seen growing clinical acceptance [12]. Electro surgically sealed vessels demonstrated clinically equivalent bursting pressures when compared with vascular staples, titanium clips, and sutures, and significantly higher pressures when compared with the scalpel in vessels in the 4-to7-mm diameter range [1518].

Vessel sealing with electro surgery has found favor in a variety of general surgical procedures, including splenectomy, thyroidectomy, hepatic lobectomy, pulmonary resection, hemorrhoidectomy, gastric resection, and nephrectomy. Romano and associates reported success using the Ligature Vessel Sealing System (Valleylab) in performing laparoscopic splenectomy on ten patients [19]. In addition, operative time was significantly lower, as was average amount of intraoperative bleeding. Head and neck surgeons have shown very favorable results when using the LigaSure electrosurgical vessel sealing in thyroidectomy, demonstrating reduced operating times and incision length $[20,21]$. The Liga Sure has also been successfully used in hepatectomy [22]. In a series of six patients (three right, two left, and one partial hepatectomy), the LigaSure was used with rapid and effective results, demonstrating minimal blood loss from the cut surface and without morbidity or mortality [23]. Similarly, we have demonstrated a low complication rate and low operative blood loss using vessel-sealing techniques.

\section{Conclusion}

From the analysis of our data, we concluded that there is strong difference in the mean pain score comparing scalpel verses diathermy in head and neck surgeries on 1st postoperative day. Nowadays, diathermy is highly preferred elective procedure for head and neck surgeries as it is associated with reduced post-op pain which was also observed in our study. Care should be taken for post-operative pain management and superficial infections after performing appropriate technique of surgery.

\section{References}

1. Chau JKM, Dzigielewski P, Mlynarek A, Cote DW, Allen H, et al. (2009) Steel scalpel versus electrocautery blade: comparison of cosmetic and patient satisfaction outcomes of different incision methods. Journal of Otolaryngology Head \& Neck Surgery 38(4): 427-433.

2. Walen SG, Rudmik LR, Dixon E, Matthews TW, Nakoneshny SC, et al. (2011) The utility of the harmonic scalpel in selective neck dissection: a prospective, randomized trial. Otolaryngology--Head and Neck Surgery 144(6): 894-899.

3. Kásler M, Remenár E, Lengyel CG, Boér A (2008) Laser surgery of head and neck lesions at the National Institute of Oncology, Budapest. Magyar onkologia 52(2): 171-176.

4. Wangensteen $\mathrm{OH}$, Wangensteen SD (1978) The rise of surgery: from empiric craft to scientific discipline 65(4): 530.

5. Bovie RM (1979) The man and the machine. Ann Plast Surg 2(2): 135153.

6. Soderstrom R (1997) Principles of electro surgery as applied to gynecology. Te Lindeâ€ $€^{\mathrm{TM}} \mathrm{s}$ operative gynecology $\left(8^{\mathrm{th}} \mathrm{edn}\right)$ Philadelphia: Lippincott-Raven pp. 321-326.

7. Smith TL, Smith JM (2001) Electrosurgery in otolaryngology-head and neck surgery: principles, advances, and complications. The Laryngoscope 111(5): 769-780.

8. Salami A, Dellepiane M, Bavazzano M, Crippa B, Mora F, et al. (2008) New trends in head and neck surgery: a prospective evaluation of the Harmonic Scalpel. Medical Science Monitor 14(5): I1-I5.

9. Eisele D, Smith R 92009) Complications in head and neck surgery. Complications in Head and Neck Surgery with CD Image Bank: Elsevier Inc, USA.

10. Orgill R, Krempl GA, Medina JE (2002) Acute pain management following laryngectomy. Arch Otolaryngol Head Neck Surg 128(7): 829-832.

11. Kumar V, Tewari M, Shukla HS (2011) A comparative study of scalpel and surgical diathermy incision in elective operations of head and neck cancer. Indian journal of cancer 48(2): 216-219.

12. Pearlman NW, Stiegmann GV, Vance V, Norton LW, Bell RCW, et al (1991) A prospective study of incisional time, blood loss, pain, and healing with carbon dioxide laser, scalpel, and electrosurgery. Archives of surgery 126(8): 1018-1020.

13. Kearns SR, Connolly EM, McNally S, McNamara DA, Deasy J (2001) Randomized clinical trial of diathermy versus scalpel incision in elective midline laparotomy. British Journal of Surgery 88(1): 41-44.

14. Prgomet D, Janjanin Sa, Bilï̈ł M, PrstaÄï̈ł R, KovaÄ L, et al. (2009) A prospective observational study of 363 cases operated with three different harmonic scalpels. European archives of oto-rhinolaryngology 266(12): 1965. 
15. Kennedy JS, Stranahan PL, Taylor KD, Chandler JG (1998) Highburst-strength, feedback-controlled bipolar vessel sealing. Surgical endoscopy 12(6): 876-888.

16. Harold KL, Pollinger H, Matthews BD, Kercher KW, Sing RF, et al. (2003) Comparison of ultrasonic energy, bipolar thermal energy, and vascular clips for the hemostasis of small-, medium-, and large-sized arteries. Surgical Endoscopy And Other Interventional Techniques 17(8): 12281230.

17. Landman J, Kerbl K, Rehman J, Andreoni C, Humphrey PA, et al. (2003) Evaluation of a vessel sealing system, bipolar electrosurgery, harmonic scalpel, titanium clips, endoscopic gastrointestinal anastomosis vascular staples and sutures for arterial and venous ligation in a porcine model. The Journal of urology. 169(2): 697-700.

18. Takada M, Ichihara T, Kuroda Y (2005) Comparative study of electrothermal bipolar vessel sealer and ultrasonic coagulating shears in laparoscopic colectomy. Surgical Endoscopy and Other Interventional Techniques 19(2): 226-228.

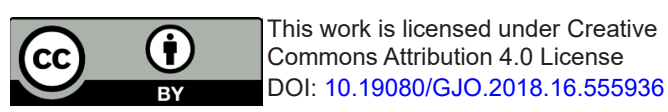

19. Romano F, Caprotti R, Franciosi C, Fina S, Colombo G, et al. (2002) Laparoscopic splenectomy using ligasure. Surgical endoscopy 16(11): 1608-1611.

20. Petrakis IE, Kogerakis NE, Lasithiotakis KG, Vrachassotakis N, Chalkiadakis GE (2004) LigaSure versus clampâ€ andâ€ tie thyroidectomy for benign nodular disease. Head \& neck 26(10): 903909.

21. Shen WT, Baumbusch MA, Kebebew E, Duh QY (2005) Use of the electrothermal vessel sealing system versus standard vessel ligation in thyroidectomy. Asian journal of surgery 28(2): 86-89.

22. Strasberg SM, Drebin JA, Han DL (2002) Use of a bipolar vessel-sealing device for parenchymal transection during liver surgery. Journal of gastrointestinal surgery 6(4): 569-574.

23. Constant DL, Florman SS, Mendez F, Thomas R, Slakey DP (2004) Use of the LigaSure vessel sealing device in laparoscopic living-donor nephrectomy. Transplantation 78(11): 1661-1664.

\section{Your next submission with Juniper Publishers will reach you the below assets}

- Quality Editorial service

- Swift Peer Review

- Reprints availability

- E-prints Service

- Manuscript Podcast for convenient understanding

- Global attainment for your research

- Manuscript accessibility in different formats

( Pdf, E-pub, Full Text, Audio)

- Unceasing customer service

Track the below URL for one-step submission https://juniperpublishers.com/online-submission.php 